\title{
Determinants of rule of law in Northern and Western Europe: an empirical study
}

\begin{abstract}
This study provides evidences on the determinants of the quality of rule of law in Europe. The selection of the determinants were made based on the criteria used by Alonso and Garcimartin in identifying these factors. Dataset for 17 countries of the Nordic and Western Europe were employed. The results obtained in the estimated model using pooled mean group (PMG) allow us to pull some remarkable inferences. Firstly, education attainment appeared to have positive influence on rule of law. Secondly, income inequality and economic growth revealed significant effects on the quality of rule of law and finally, trade openness deteriorates the quality of rule of law.
\end{abstract}

Keyword: Rule of law; Determinants of the rule of law; Pooled mean group; Nordic; Western Europe 